\title{
Well-being and the Perception of Stress among EFL University Teachers in Saudi Arabia
}

\author{
Nada A. Alqarni \\ King Khalid University \\ Correspondence concerning this article should be addressed to Nada A. Alqarni, English Department, \\ Faculty of Languages and Translation, King Khalid University, King Abdullah Road, Abha, Saudi Arabia, \\ P.O. Box : 960 - Postal Code: 62221. E-mail: ndaa@kku.edu.sa
}

\begin{abstract}
Research on language teachers' psychology has been shown to play a central role in the quality of teaching and student achievement. However, there is little empirical evidence to investigate the relationship between perception of stress, types of stressors, and well-being among foreign language teachers at university levels, particularly in monolingual contexts. The present study seeks to investigate the impact of stress, the number and type of stressors (i.e., chronic and stressful life events), and demographic variables (i.e., age, gender, and the length of teaching experience) on university-level EFL teachers' levels of well-being. The data were collected through an online survey of 53 university-level EFL teachers in Saudi Arabia. A Pearson correlation was carried out to investigate the relationship between EFL teachers' well-being, their perception of stress, and number of stressors. A multiple regression analysis was also run to examine if EFL teachers' levels of stress, number and types of stressors, and demographic variables can predict their psychological well-being. The quantitative findings demonstrated a significant negative relationship between well-being and levels of stress. The findings also showed a significant positive relationship between the EFL teachers' well-being and their good physical health. The results of the multiple regression indicated that high levels of well-being were predicted by low levels of stress and good physical health. This study, moreover, suggested an advantage for females in terms of psychological well-being among foreign language teachers. The findings also demonstrated that a stressful life with a heavy workload and financial concerns can negatively impact language teachers' well-being. These findings highlight the importance of considering issues related to teachers' psychological well-being. In line with these findings, several pedagogical implications were offered.
\end{abstract}

Keywords: well-being, stress, stressors, foreign language teachers, psychology of language teaching, university language teachers in Saudi Arabia

\section{Introduction}

Although positive psychology (PP) previously focused mainly on topics related to the human experience and requirements for maintaining good health, it is a relatively new and less explored area of second language acquisition (SLA) studies. Various types of emotions and affective states emerge for both learners and teachers in language classrooms (Horwitz, 2017). Research has focused on various aspects of language learners' emotions, with the most prevalent being learners' motivation (Dörnyei \& Ryan, 2015) and anxiety (Dewaele \& Mercer, 2018). However, research on the psychology of language teachers remains "disproportionately less prevalent" (Gkonou et al., 2020, p. 3; Swain, 2013; Xu, 2018).

Research on foreign language teachers is crucial, as they are "the guides for FL learners, and without their guidance, many learners would stumble in the dark" (Dewaele, 2020, p. 269). Mercer (2018) insisted that understanding teachers' psychology is necessary "because their psychologies and professional well-being have been shown to be connected to the quality of their teaching as well as student performance" (p. 508). Teachers with positive states of mind tend to enjoy their jobs and exhibit more creativity and enhanced teaching skills (Mercer \& Kostoulas, 2018). Mercer et al. (2016) stressed that "successful language learning depends to a large degree on teachers and, as such, for all concerned, we must make their professional well-being a priority" ( $\mathrm{p}$. 224). Despite this interest, teachers' well-being remains poorly understood. 
Gkonou et al. (2020) summarised the main emotional problems that language teachers may experience, with the most common ones being "teacher stress, burnout and attrition" (p. 11). Gkonou et al. (2020) argued that these emotional experiences must be investigated in order to improve teachers' emotional competence, which will positively influence their psychological well-being and the effectiveness of their classroom teaching practices. The latter, in turn, will improve their students' academic performance.

Generally speaking, teaching is "an emotion-laden process" (Gkonou et al., 2020, p. 1; Chen, 2016; Day \& Lee, 2011; Hargreaves, 2001; Maslach, 1993), as it requires affective interaction between teachers and students in the learning environment in order to achieve expected learning and teaching outcomes (Agudo, 2018; Chen, 2016; Day \& Lee, 2001; Hargreaves, 2001). Early literature argued that teaching is a difficult occupation and that teachers are at risk of experiencing high levels of stress (Travers \& Cooper, 1997). Kyriacou (2001) defined stress as a response syndrome of negative feelings that emerge due to increased pressure and a lack of coping strategies. The concept of stress has been studied from social perspectives, such as the occurrence of illnesses as a response to the social environment that an individual is exposed to (Cohen al., 2019). Foreign language teachers in particular may be exposed to extra pressure and stress due to the challenges of helping language learners master new linguistic skills (Shah et al., 2013). However, little attention has been paid to language teachers' emotional well-being and the influence of teachers' stress and well-being on in-class practices.

Gkonou et al. (2020) called for more research on language teacher psychology. This study aimed to contribute to this area of research. The present study sought to explore the effects that levels and perception of stress have on English as a foreign language (EFL) teachers' health and well-being, focusing on the type of stressors experienced by English language teachers in Saudi Arabia. This type of foreign language teaching and learning context may cause higher psychological pressure for teachers due to learners' low levels of language proficiency and motivation (Shah et al., 2013). To date, no studies have attempted to understand the well-being, stress, and stressors of foreign language teachers in Saudi universities. This study contributes to raising awareness of the importance of understanding the psychology of language teaching and the stressors faced by foreign language university teachers in Saudi Arabia.

\section{Literature Review}

\section{Language Teacher Psychology}

A considerable body of research exists on language teacher psychology, particularly focusing on cognition (Borg, 2003), identity (De Costa \& Norton, 2017; Norton, 2000), motivation (Dörnyei, 2005), and self-efficacy (King, 2016; White, 2016). Recently, research inspired by positive psychology (MacIntyre et al., 2019; Williams et al., 2016) produced a range of studies on the professional lives of teachers (Day \& Gu, 2014; Hiver \& Dörnyei, 2017), including the role of teachers' emotional and social intelligences in learning processes (Elias \& Arnold, 2006) and in teacher well-being (Day \& Gu, 2009; Gkonou \& Mercer, 2017).

As Williams et al. (2016) argued, foreign language teachers' beliefs, personality traits, sense of self, emotions, confidence, and relationships with other peers impact their behaviours and interactions in the classroom. Williams et al. (2016) stated that, "Nobody becomes who they are in a vacuum, separate and distinct from cultural and contextual influences” (p. 93) and that teachers' behaviour, which is influenced by internal and external factors, likely impacts their learners' performance in the language learning process. A multitude of environmental factors impact both language learners' and teachers' psychological states, such as the time of day, the weather, and other classes taking place before, during, and after the language classes (Williams et al., 2016).

Furthermore, teaching processes are influenced by teachers' personal views of teaching practices, methods, and activities used in the classroom, their interactions with their learners, and their expectations of their learners, which are influenced by teachers' understanding of psychological processes involved in learning (Williams et al., 2016). As such, language teachers require psychological awareness, as it helps them "to feel better equipped to teach with empathy and sensitivity to the needs, drives, and emotions of their learners" (Williams et al., 2016, p. 17). 
Positive psychology generally aims to "help people live happier, more fulfilling lives by focusing on what goes well in life" (MacIntyre et al., 2019, p. 28). Positive psychology focuses on factors that contribute to helping teachers and learners enjoy teaching and learning experiences and maintain high levels of well-being (MacIntyre \& Gregersen, 2012; MacIntyre et al., 2019). However, Oxford (2020) recently argued that "contributions to teachers' emotional well-being come not only from pleasant emotions but also from painful ones" (p. 263). This paper focuses on understanding English language teachers' sense of well-being, considering the effects of their perception of stress and identifying the types of stressors they may experience.

\section{Perception of Well-being}

One of the reasons that people engage in teaching or learning languages is related to emotional well-being (MacIntyre et al., 2019). Well-being here is defined as the "empowering product" that "can facilitate not only personal transformations but also societal transformations” (p. 266). Seligman's $(2002,2011)$ well-being theory focused on positive emotions that broaden individuals' personal opportunities and develop their skills and competencies (Fredrickson, 2004; Seligman, 2011). According to Seligman (2011), the purpose of the well-being theory was "to increase flourishing by increasing positive emotions, engagement, meaning, positive relationships and accomplishment" (p. 12). For Seligman (2011), well-being is a construct of certain elements, namely, positive emotion, engagement, relationships, meaning, and accomplishment (PERMA). Positive emotions include pleasure, warmth, and comfort. Engagement refers to being in a state of flow (i.e., being absorbed in whatever one is doing). Positive relationships are those relationships that "give meaning and purpose to life" (Seligman, 2011, p. 17). Meaning indicates having a purpose in life that goes beyond one's self. Accomplishment, refers to feeling competent at achieving one's goals (Seligman, 2011).

One of the primary elements of well-being is meaning. Teachers who feel that their lives, particularly in their jobs, are meaningful, can invest their energies in achieving valuable goals, which contributes to their overall well-being (Chan, 2013; Falout \& Murphey, 2018). Falout and Murphey (2018) demonstrated how language teachers actively make their jobs more meaningful through a process of job crafting, which involves changing tasks, relationships, and roles associated with work. They argued that teachers can exert control over their well-being in order to cope with the challenges of the profession. Therefore, coping with professional challenges appears to be related to emotional will-being.

Social factors have been found to impact teachers' psychological well-being. For instance, studies have found that positive social support from colleagues and supervisors in the workplace can help teachers manage their well-being and experience positive emotions (Cherkowski \& Walker, 2018; Le Cornu, 2013; Weiland, 2021). Moreover, cross-cultural differences, such as situations where teachers' own culture clashes with the culture of their workplace, can add extra pressure and may impact teachers' well-being. Dodge et al. (2012) argued that adapting more flexibly to a new culture may help teachers "reconstruct their identities and expectations in ways that affected their well-being positively" (p. 10). In addition, educational, social, and ideological variations between teachers' heritage and contextual cultural norms must be considered when investigating teachers' well-being (Dodge et al., 2012).

\section{Well-being and Psychological Factors}

Apart from social and cultural factors, individual psychological traits can contribute to determining teachers' well-being, positive emotions, and degree of classroom enjoyment. Studies have reported that high levels of self-efficacy, optimism, self-esteem, and resilience positively influence teachers' well-being (Dodge et al., 2012; MacIntyre et al., 2019; Mercer et al., 2016). Furthermore, having a positive outlook with a sense of gratitude, being optimistic, and experiencing more positive emotions help teachers achieve higher levels of well-being, build healthier relationships in the workplace, and cope with stress (Dodge et al., 2012; Jin et al., 2021). Dewaele et al. (2019) found that language teachers who remain positive and encourage students positively impact students' academic performance in language learning classrooms.

Dewaele and Mercer (2018) found that language teachers with high emotional intelligence reported more positive attitudes toward their students. In addition, they argued that more teaching experience boosted teachers' emotional intelligence and led to positive emotions and enjoyment in the classrooms. Similarly, Dewaele (2020) found that teachers with high emotional intelligence, particularly in terms of well-being, 
emotionality, self-control, and sociability, tended to report high levels of motivation in language classrooms. As such, positive emotions and well-being seemed to determine the quality of language teaching and learning. Teachers' well-being, therefore, is necessary for quality teaching instruction and improving students' academic and learning success (Hiver, 2015).

Hiver (2016) investigated novice second language teachers and concluded that the main reason for leaving the profession during the first year was the "experience of compounding futility and hopelessness that failed to reverse itself" (p.188). On the other hand, for those novice teachers who believed that hope can be regained, "developing the capacity to generate goals and produce pathways to those goals mitigated feelings of alienation and powerless, and allowed them to establish a sense of control over life events" (p.188) is critical. Moreover, their goals allowed them "to establish a sense of control over life events" (p.188). Hiver (2016) suggested that open interactions among situational factors may lead to emergent outcomes associated with the mechanisms of hope and hardiness, provide novice second language teachers with a positive sense of meaning in life, and allow them to anticipate flows in their profession.

As such, investigations into teachers' well-being can help determine how they can effectively achieve their teaching goals. Extant studies suggest that teachers' well-being strongly affects the ways they behave, how they engage with their learners in the classroom, and their willingness to persevere in the face of difficulties (MacIntyre \& Gregersen, 2012; MacIntyre et al., 2019; Williams et al., 2016). Crucially, their perceptions of their feelings and well-being lie at the core of their ability to regulate their emotions, monitor and evaluate their own behaviours, and select appropriate teaching strategies. Extant literature indicates that the perception of well-being is a crucial tool for language teachers (Day \& Gu, 2014; Hiver \& Dörnyei, 2017). However, there remains a gap in our understanding of the impact of negative psychological factors, such as stress, on teachers' emotions and well-being.

\section{Perception of Stress and Stressors}

Several studies have found that challenges faced by foreign language teachers in language classrooms, such as large class size, high expectations from language learners, learners' low language proficiency, lack of appropriate teaching and learning materials, and lack of socio-cultural and contextual knowledge, were likely to cause stress and result in low expectations, negatively impacting foreign language teachers' performance (Hall, 2017; Peng, 2007; Shah et al., 2013; Yu, 2001). Occupational stress is a significant factor influencing teachers' well-being (Jepson \& Forrest, 2006). Long-term occupational stress can lead to a psychological state called job burnout (Jepson \& Forrest, 2006). Burnout is caused by the gap between high expectations of successful professional performance and reality, resulting in "emotional exhaustion, depersonalization, and reduced personal accomplishment” (Maslach, 1993, pp. 20-21). High levels of stress can lead to physiological or psychosomatic symptoms (Cohen et al., 2019) and mental illnesses (Yaribeygi et al., 2017).

Prolonged stress amongst teachers may lead to chronic illness and burnout and, consequently, may negatively influence job satisfaction (Reilly et al., 2014). Stressors may stem from work-related aspects, such as initiative overload, a target-driven culture, students' behaviour, and high expectations (Brown et al., 2002), and negative environmental and occupational factor, such as role conflicts (Mérida-López et al., 2017), disagreements with colleagues (Wolgast \& Fischer, 2017), heavy workloads or long working hours (van Dick \& Wagner, 2001; Werang, 2018), inconsistent workloads over the academic year (Skaalvik \& Skaalvik, 2017), and evaluation apprehension (Randall, 2019).

Although teachers may be exposed to similar stressors, their reactions vary, as they may be influenced by individual differences, such as cross-cultural differences, personality traits, gender, age, and teaching experience (Gardiner \& Tiggemann, 1999; Jepson \& Forrest, 2006; Travers \& Cooper, 1997). For instance, novice teachers were found to have higher levels of stress than their more experiences colleagues (Herman et al., 2018). Some studies showed that women may be at a higher risk of experiencing stress, particularly in terms of heavy workloads and long working hours, than men (Sak, 2018; van Dick \& Wagner, 2001), while others found no gender differences regarding stress levels (Evers et al., 2002; Jepson \& Forrest, 2006). Jepson and Forrest (2006) showed that teachers with substantial teaching experience were more adept at using coping skills to deal with stress and concluded that occupational stressors have a negative influence on those teachers who "strive for high levels of achievement" (p. 193). In addition, social factors, such as peer support, tend to 
impact foreign language teachers' stress. Acheson et al. (2016) found that teachers appreciated peer support more than administrative support and that a lack of emotional and social support and encouragement from peers regarding achievements may lead to higher levels of stress, causing job burnout.

There is a growing body of literature on the relationship between stress and psychological factors, such as selfefficacy, among foreign language teachers in various educational contexts (Mede, 2009; Vaezi \& Fallah, 2011). However, the relationship between well-being and the perception of stress as well as stressors among foreign language teachers in Saudi Arabia have not been investigated in depth. This paper sought to address this issue.

\section{English Language Teaching in Saudi Arabia}

English language classrooms in Saudi Arabian universities include learning materials and participants with different language histories, and cultural and psychological backgrounds (Al-Seghayer, 2014). Language learners' psychological characteristics have been investigated widely in Saudi Arabian contexts (Javid et al., 2012; Moskovsky \& Alrabai, 2009; Moskovsky et al., 2016). Furthermore, some studies have found that language teachers working in Saudi Arabia face a number of challenges (Al-Seghayer, 2014; Rehman \& Alhaisoni, 2013; Shah et al., 2013). For instance, English language teachers may "feel unequipped to handle uncertain pedagogical and socio-cultural issues which crop up during the teaching and learning process" (Shah et al., 2013, p. 105). Shah et al. (2013) identified three factors influencing English language teaching in Saudi Arabia: (1) social, cultural, and religious sensitivities (e.g., the conservative and religious nature of Saudi society), (2) English language learners' lack of motivation, low language proficiency, and negative attitudes towards English language learning, and (3) unfavourable institutional policies and procedures (e.g., inconsistent attendance policies). English language teachers, especially non-Arabs, often do not discuss any cultural and religious topics with their students "to avoid frustration and drastic consequences" (Shah et al., 2013, p. 107), causing cross-cultural misunderstandings among English language teachers and their students and potentially adding to emotional stressors.

"Teaching involves understanding the dynamics and relationships within the classroom and the rules and behaviours specific to a particular setting" (Shah et al., 2013, p. 107). Thus, one of the stressors that non-Arabic (English) language teachers might experience stems from difficulties in understanding Saudi language learners' culture. In this case, English language teachers may need to develop cultural awareness and increase contextual knowledge, which may improve their psychological states.

Al-Seghayer (2014) highlighted four English language teaching constraints in Saudi contexts: learners' beliefs and expectations regarding learning English; preparation programmes and teaching methods that may not provide adequate training for the pre-service teachers; curricula that include limited time for instruction, limited resources for learning materials, and constraints concerning teaching and learning standards; and the excessive centralisation of administration (e.g., an identical syllabus with guidelines given to English language teachers at each grade level by the Ministry of Education). These constraints may add extra complexity to language teaching, particularly in a monolingual Arabic country, such as Saudi Arabia.

Therefore, English language teachers face a lot of challenges, particularly due to the nature of the Saudi Arabian educational context and linguistic environment, where language learners' English proficiency is considerably low (Mehmood, 2019). Consequently, English language teachers in most Arab countries in general and Saudi Arabia in particular require a variety of teaching methods due to the learners' low proficiency levels and a lack of motivation (Rehman \& Alhaisoni, 2013). Mehmood (2019) maintained that English language teachers receive a major shock regarding their students' low language proficiency levels. In most cases, motivating the learners to improve their language proficiency is challenging for the teachers, creating additional psychological pressure. It can be hypothesised that English language educators are under more pressure and stress than other teachers, which may negatively impact their emotional well-being and their mental and physical health. This raises many questions regarding the correlation between English language teachers' well-being, perception of stress, and number and types of stressors.

There remain several gaps in the current research on the psychology of language teachers in Saudi Arabia. In order to address these gaps, the present study aimed to examine the impact of stress, the number of stressors, 
and demographic variables (i.e., age, gender, and length of teaching experience) on English language university teachers' well-being in Saudi Arabia.

The following research questions were posed:

RQ1: What is the relationship between English language teachers' well-being and their perception of stress, the number of stressors, and their demographic variables (e.g., age, gender, and years of teaching experience)?

RQ2: What are the levels of English language teachers' perception of stress and the most frequent stressor(s)?

RQ3: Is there a correlation between English language teachers' perception of stress and their stressors?

\section{Methodology}

This study adopted a cross-sectional design using an online questionnaire distributed to the participants.

\section{Participants}

A total of $53(N=53)$ English language teachers (19 men and 34 women) working as instructors at King Khalid University in Saudi Arabia participated in this study. Their ages ranged from 25 to 56 years old $(M=34.27, S D=$ 5.9). Of the participants, 24 were Saudi, while 29 were of other nationalities: 12 Arabs but non-Saudis, six Indians, five Bangladeshis, three Pakistanis, two Canadians, and one American. Their years of teaching experience ranged from one year to 33 years $(M=12.58, S D=7.2)$. The majority $(43.4 \%)$ had a PhD, while $41.5 \%$ had a master's degree.

All of the participants worked as instructors in the English department, where English was taught as a foreign language. The students in the department were placed in different classes and levels (level 1 to level 8), taking English courses for a maximum of 24 hours per week. The English language courses varied from basic language skills (reading, writing, listening, speaking, and grammar) to more advanced courses in Linguistics, Applied Linguistics, English Literature, and Arabic-English translation.

\section{Instruments}

This study used a questionnaire that was distributed online. It consisted of four parts:

Part 1: Teacher's demographic information consisted of questions to gather information on each teacher's demographic information (i.e., age, gender, occupation, nationality, and years spent teaching English).

Part 2: PERMA-Profiler measure (Butler \& Kern, 2014) consisted of 23 items based on nine factors: positive feelings (3 items), engagement (3 items), relations (3 items), meaning (3 items), accomplishment (3 items), negative emotion (3 items), physical health (3 items), happiness (1 item), and loneliness (1 item). A composite score for well-being was derived by averaging the standardised scores for the first five factors of the PERMAProfiler measure: positive feelings, engagement, relations, meaning, and accomplishment. The other variables were measured as individual factors in relation to other variables in the study. The composite variable parallels the perception of well-being (Butler \& Kern, 2014).

Part 3: Perceived Stress Scale (Cohen et al., 1983) consisted of 10 items to measure participants' current levels of experienced stress. It measured to what extent participants found their lives to be unpredictable, uncontrollable, or overloaded. The 10 items enquired about participants' feelings and thoughts over the last month. Each item was accompanied by a five-point Likert-type scale ranging from never (1) to very often (5). A composite score for stress levels was derived by averaging the standardised scores for the 10 items in the scale. The composite variable paralleled the perception of stress (Cohen et al., 1983). A high score on this scale indicated a high level of stress.

Part 4: Stressors consisted of a multiple-choice question about the participants' most frequent stressor(s). The participants could choose one or more of the 17 items that represented the stressor(s) they may suffer from. The stressors were classified into two types:a) chronic stressors (insufficient income, heavy workloads, long 
working hours, and a lack of job security); and b) stressful life/work events (changes in employment, conflicts at work, a lack of peer support, inadequate supervision, an over-emphasis on results, work performance, having the same daily routine and work-life balance, and physical or health problems). Most of the chronic stressors were adapted from Jones et al. (2001, pp. 26-27). Most of the stressful life events were adapted from Jones et al. (2001, pp. 21-24) and Holmes and Rahe's (1967, p. 213) social readjustment rating scale.

\section{Procedures}

The study was carried out during the Autumn term of the 2019-2020 academic year. The recruitment of the participants was performed through a snowball sampling technique, which is a form of non-probability sampling (Rooney \& Ness Evans, 2018). Using this technique, the participants were asked to forward the online survey to their colleagues and friends who were English language teachers at King Khalid University, Saudi Arabia. One of the advantages of an online questionnaire is that it allowed for the collection of large amounts of data from participants with various backgrounds in a period of short time (Dörnyei, 2007).

The online survey was conducted in English and took about 15 minutes to complete. Instructions were given at the beginning of the survey, and confidentiality and anonymity were ensured to encourage honest responses. Participation was voluntary. The research design and questionnaire received ethical approval from the ethics board at the author's research institution.

\section{Data Preparation and Analysis}

Prior to the statistical analysis, the data were statistically analysed for reliability. Cronbach's alpha for the PERMA-Profiler scale was good $(\alpha=.91)$. The reliability estimate for the Perceived Stress Scale was also good $(\alpha$ $=.89$ ). The normality test was performed using the Shapiro-Wilk test because the sample size was small. Based on the Shapiro-Wilk test results, the data were normally distributed (PERMA-Profiler scale: 0.974, $p=.30$; Perceived Stress Scale: 0.965, $p=.11$ ); therefore, parametric tests could be used for the data analyses. All statistical calculations in this research were performed using the Statistical Package for the Social Sciences (SPSS, ver. 21). In order to examine the impact of the independent variables (the perception of stress, negative emotions, health, the number of stressors, gender, age, and teaching experience) on the main dependent variable (the perception of well-being), the quantitative data were analysed statistically using the multiple regression analysis. Pearson correlational tests were used to examine the relationships between the variables. To compare the perception of well-being between male and female English language teachers, a $t$-test was carried out.

\section{Results}

The data were analysed using multiple regression analysis to predict English language teachers' levels of wellbeing (PERMA) based on a number of predictors (perception of stress, negative emotion, health, and the number of stressors) ${ }^{1}$. Because the perception of stress was one of the variables of interest in terms of predicting well-being, it was entered into the first block of predictors. The second block contained the other variables (negative emotions, health, and the number of stressors). The third block contained the participants' personal variables (age, gender and teaching experience).

\section{English Language Teachers' Well-Being}

The regression analysis produced a sample multiple correlation coefficient of .80, indicating that approximately $64.7 \%$ of the total variance in the levels of well-being could be explained by the predictor variables, $F(7,52)=$ $11.77, p<.001$. In the first block, the perception of stress was significant $(p<.001)$, explaining $39 \%$ of the total variance (see Table 1 ). In the second block, the effect of health was strongly significant, $\beta=0.51, p<.001$. In the third block, the perception of stress, health and gender were significant, all with $p<.01$. In particular, the levels of well-being were negatively predicted by the perception of stress and positively predicted by good physical

\footnotetext{
Borg and Gall (1989) suggested that a minimum sample size of 30 can be used for testing correlation. This sample size can also be used for parameter estimates in regression analysis (Raykov \& Widaman, 2009). Although the sample size of this study is not large, it still meets the minimum requirement. In addition, to avoid a meaningless solution, the number of predictors in the regression analysis was minimised.
} 
health and gender, $\beta s=-0.34$ and 0.42 , respectively, and $p<01$. However, age, years of teaching experience, and the number of stressors were not significant.

Further Pearson correlational analyses showed that the total score of the PERMA was negatively and significantly correlated with the perception of stress $(r=-0.63, p<.0001)$, negative emotions $(r=-0.41, p<.001)$, and the number of stressors $(r=-.034, p<.01)$. However, it was positively and significantly correlated with the good physical health $(r=0.71, p<.0001)$.

\section{Table 1}

Regression model for well-being (PERMA-Profiler) $(N=53$ EFL teachers in Saudi Arabia)

\begin{tabular}{|c|c|c|c|c|}
\hline & Model & $B$ & Std. E & $\beta$ \\
\hline \multirow[t]{2}{*}{1} & (Constant) & 10.96 & 0.57 & \multirow{2}{*}{$-0.63^{* * * * *}$} \\
\hline & Perception of Stress & -1.19 & 0.20 & \\
\hline \multirow[t]{5}{*}{2} & (Constant) & 6.07 & 1.32 & \multirow{2}{*}{-0.27} \\
\hline & Perception of Stress & -0.51 & 0.27 & \\
\hline & Negative emotions & 0.03 & 0.09 & 0.04 \\
\hline & Health & 0.41 & 0.10 & $0.51^{* * * * *}$ \\
\hline & Number of stressors & -0.08 & 0.08 & -0.10 \\
\hline \multirow[t]{8}{*}{3} & (Constant) & 5.64 & 1.32 & \multirow{2}{*}{$-0.34^{* * *}$} \\
\hline & Perception of Stress & -0.65 & 0.25 & \\
\hline & Negative emotions & -0.03 & 0.08 & -0.05 \\
\hline & Health & 0.34 & 0.09 & $0.42^{* * * *}$ \\
\hline & Number of stressors & -.006 & 0.07 & -0.008 \\
\hline & Age & -0.03 & 0.19 & -0.02 \\
\hline & Gender & 0.83 & 0.28 & $0.29 * *$ \\
\hline & Teaching experience & 0.01 & 0.02 & 0.09 \\
\hline
\end{tabular}

Note: $\mathrm{R}^{2}=0.63, \Delta \mathrm{R}^{2}=0.39, \mathrm{~F}$ Change $=33.84^{* * * *}$ for Model 1 .

$\mathrm{R}^{2}=0.74, \Delta \mathrm{R}^{2}=0.55$, F Change $=5.79 * *$ for Model 2.

$\mathrm{R}^{2}=0.80, \Delta \mathrm{R}^{2}=0.64, \mathrm{~F}$ Change $=3.74^{* * * * *}$ for Model 3.

$\left({ }^{*} \mathrm{p}<.05 . * \mathrm{p} p<.01 . * * * \mathrm{p} p<.001\right)$.

\section{Well-Being and Gender}

A $t$-test indicated a slightly significant difference between women $(M=8.04, S D=1.1)$ and men $(M=7.16, S D=$ $1.6)$ in their levels of well-being, with the former reaching higher levels of well-being than the latter $(t(53)=$ $-2.24, p \leq .02)$.

\section{English Language Teachers' PERMA-Profiler}

As the graph below indicates, the participants reported the highest scores in two dimensions of PERMA: the meaning factor $(S D=1.49)$ and the accomplishment factor $(S D=1.47)$. Overall, the participants scored highly in all PERMA factors and had a mean score of $7.73(S D=1.36)$ on the PERMA scale (see Figure 1).

\section{English Language Teachers' Perception of Stress and Frequent Stressor(s)}

Overall, the participants reported low levels of stress perception, with a mean score of $2.7(S D=.72)$. Their perception of stress was positively and significantly correlated with the number of stressors $(r=.397, p<.003)$, with those who reported higher levels of stress appearing to have a larger number of stressors. An additional correlation analysis showed a positive and moderate correlation between the perception of stress and stressful work events $(r=.315, p=.02)$.

Participants' perception of stress was also negatively and significantly correlated with the health factor of the PERMA-Profiler $(r=-.654, p<.0001)$, with those suffering from high levels of stress seeming to have more physical and health problems than those with low levels of stress (see Figure 2). 
Figure 1

Mean scores of the PERMA-Profiler for EFL teachers $(N=53)$

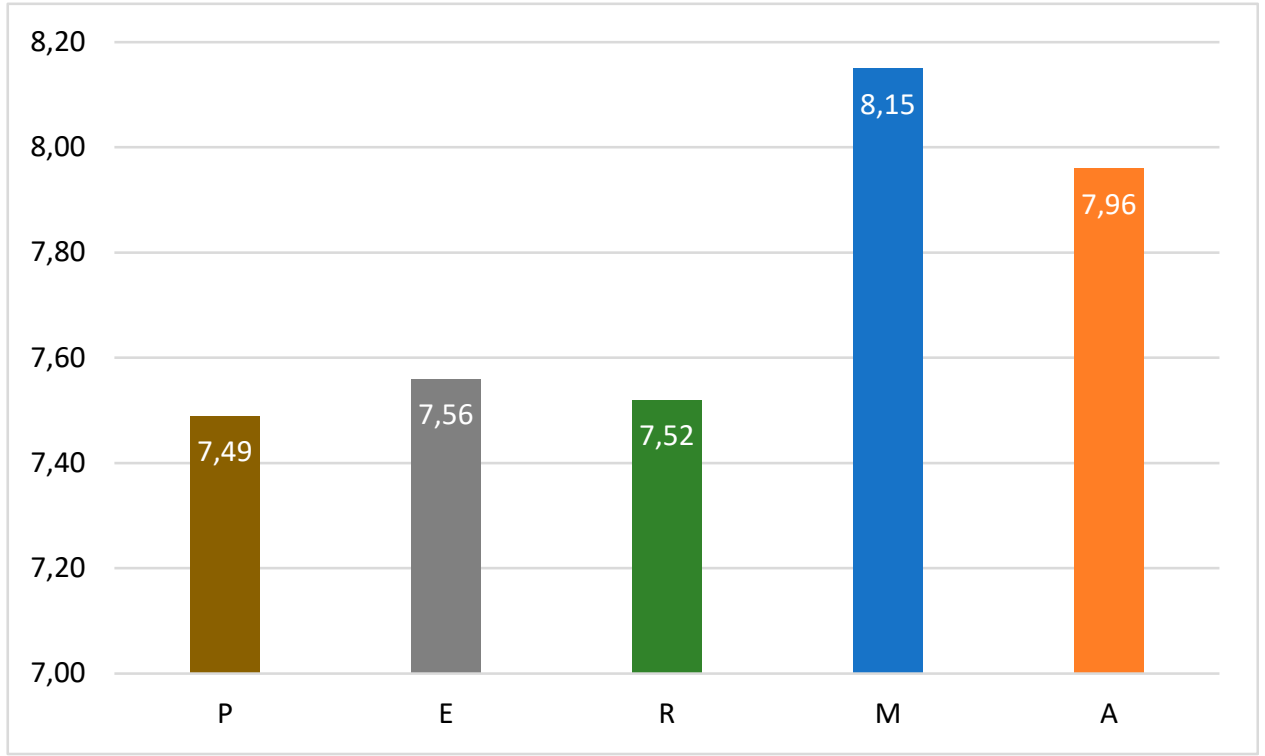

Figure 2

Correlation between the factors Health and the Perception of Stress among the participants $(N=53)$

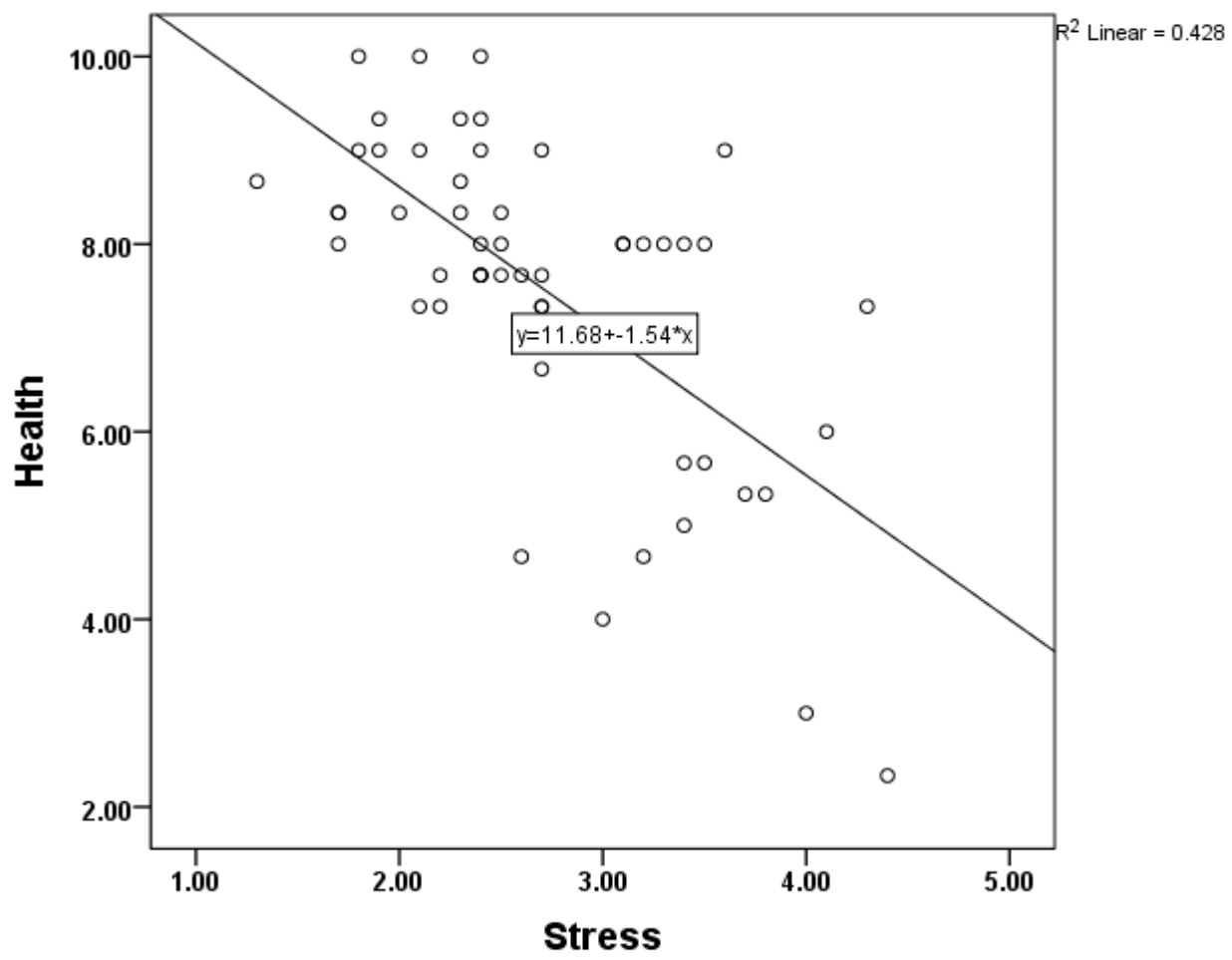

It can be observed from the table below (Table 2) that heavy workload is the most frequent stressor (52.8\%), followed by the difficulty maintaining work-life balance (26.4\%). However, the participants who chose these two stressors reported high levels of well-being and moderate levels of stress perception. It can be noticed that those participants who had physical or health problems as their main stressors reported high levels of stress. The same case was found with the participants who had financial stressors. These types of stressors seem to have a statistical relationship with the levels of stress perception. 
Table 2

Frequency and percentages of stressors and mean scores and standard deviations of the PERMA-Profiler and Perception of Stress based on the type of stressors

\begin{tabular}{|c|c|c|c|c|}
\hline Stressors & $\begin{array}{c}\text { Frequency } \\
(N=53)\end{array}$ & Percent (\%) & $\begin{array}{c}\text { PERMA } \\
\text { (SD) }\end{array}$ & $\begin{array}{l}\text { STRESS } \\
\quad(S D)\end{array}$ \\
\hline Financial stressors & 10 & 18.9 & $6.87(1.92)$ & $3.07(.80)$ \\
\hline Heavy workload & 28 & 52.8 & $7.6(1.51)$ & $2.7(.69)$ \\
\hline Long working hours & 8 & 15.1 & $7.56(1.23)$ & $2.97(.77)$ \\
\hline Change in employment & 2 & 3.9 & $7.93(.09)$ & $3.7(.84)$ \\
\hline Lack of job security & 11 & 20.8 & $7.35(1.96)$ & $2.85(.80)$ \\
\hline Administration & 3 & 5.7 & $7.42(1.10)$ & $2.96(.46)$ \\
\hline Inadequate supervision at work & 4 & 7.5 & $8.25(.79)$ & $2.77(.56)$ \\
\hline Lack of progression opportunities & 8 & 15.1 & $6.58(1.67)$ & $3.13(.88)$ \\
\hline Over emphasis on results & 12 & 22.6 & $7.72(1.30)$ & $2.98(.86)$ \\
\hline Work performance & 1 & 1.9 & $8.93(0)$ & $2.10(0)$ \\
\hline Same daily routine & 5 & 9.4 & $7.57(1.09)$ & $2.88(1.13)$ \\
\hline Conflict at work & 7 & 13.2 & $7.46(1.26)$ & $3.08(.67)$ \\
\hline Disagreement with colleagues & 2 & 3.8 & $4.86(2.07)$ & $3.75(.35)$ \\
\hline Lack of peer support & 5 & 9.4 & $7.46(1.27)$ & $2.8(.59)$ \\
\hline Poor cultural background & 1 & 1.9 & $6.86(0)$ & $3.7(0)$ \\
\hline Work-life balance & 14 & 26.4 & $7.38(.92)$ & $2.83(.74)$ \\
\hline Physical/health problems & 9 & 17 & $7.28(2.02)$ & $3.14(.70)$ \\
\hline
\end{tabular}

\section{Discussion}

One of the central aims of this study was to examine the relationship between English language teachers' wellbeing and variables such as the perception of stress, the number of stressors, and the demographic variables (i.e., age, gender, and years of teaching experience). The quantitative findings demonstrated that the selected predictors were significant in terms of predicting emotional well-being among English language teachers. In other words, high levels of well-being were predicted by low levels of stress and good physical health.

The perception of stress explained a further $39 \%$ of the variance, meaning that it was one of many psychological and environmental variables that may impact well-being scores. The findings indicated a significant impact of stress on English language teachers' well-being, supporting previous studies that showed the negative effects of stress on various psychological aspects (Acheson \& Nelson, 2020; De Costa et al., 2020; Hall, 2017). These findings constituted the main contribution of this study. The findings indicated that extra pressure and occupational stress put on English language teachers in the Saudi Arabian context may lead to low levels of well-being. Nevertheless, it must be stressed that the relationship between the variables of stress and wellbeing was not a causal one.

One of the notable findings from this study was the significant and negative impact of the number of stressors on the English language teachers' well-being. The findings suggest that those English language teachers who suffer from many stressors, such as financial and chronic stressors and stressful life events, demonstrate lower levels of well-being compared to their peers who experience a smaller number of stressors. Among the demographic variables, only gender indicated a significant difference between English language teachers, with women scoring higher on the PERMA scale than men. This result does not align with earlier studies that did not find any significant differences between men and women regarding engagement in emotional labour (Acheson \& Nelson, 2020; Jepson \& Forrest, 2006). There was also no significant impact of gender on the levels of stress or number of stressors found in this study. On the other hand, several previous studies reported gender differences in terms of job burnout and levels of stress (van Dick \& Wagner, 2001) among foreign language teachers, with women reporting negative effects of these psychological problems. 
The present study contributes to this field by adding the possibility of gender differences to positive psychological aspects, such as well-being. It can be assumed that female foreign language teachers might possess skills and certain cognitive strategies to manage their well-being (Talbot \& Mercer, 2018). This sheds light on the importance of adapting cognitive strategies and skills related to well-being management and developing other skills to cope with stressful life or work events, particularly in the field of education and language teaching training.

In addition, the findings revealed a significant positive relationship between the perception of well-being and general health, indicating a positive impact of emotional well-being on English language teachers' physical health. In other words, the findings suggested that English language teachers with higher levels of well-being have better physical health. This was in line with previous studies on the importance of maintaining well-being among teachers for good physical and mental health as well as effective teaching performance (Hiver, 2015).

Furthermore, it was expected that due to the challenges reported by previous studies on English language teachers in Saudi Arabia (Al-Seghayer, 2014; Rehman \& Alhaisoni, 2013; Shah et al., 2013), the participants may have high levels of stress. However, the findings showed that most participants reported low levels of stress. This may be attributed to the participants' years of experience, as most of them had been in their jobs for more than 12 years. It supports other studies that suggest that substantial teaching experience leads to adapting coping skills to overcome job stress and negative feelings generated from teaching foreign language learners (Jepson \& Forrest, 2006).

This study shed light on some of the chronic stressors and stressful life and work events experienced by university English language teachers in Saudi Arabia. The most frequent stressor was the heavy workload, in line with the findings of previous studies (van Dick \& Wagner, 2001; Werang, 2018). Heavy workloads and long working hours may lead to high levels of stress and impact English language teachers' job motivation. It should be noted that the average working hours in Saudi universities range from 20 to 40 hours per week. English language teachers may also have other responsibilities, such as preparing teaching materials and academic and management duties. Other frequent stressors reported by the participants were difficulty maintaining a worklife balance and an over-emphasis on work performance. Among these chronic stressors, financial stressors seemed to generate high levels of stress and result in low levels of well-being. Poor physical health was also found to be related to low levels of well-being and high levels of stress perception. These occupational and personal stressors were likely to influence teachers' long-term performance and achievement (Jepson \& Forrest, 2006).

These findings suggested that strategies to cope with such stressors should be a core concern of teachers and educational stakeholders. Educational programmes that incorporate elements of affective training to help foreign language teachers face various emotional and professional difficulties should be introduced. For instance, educational programmes that may target teachers' emotional and social skills should be included in the educational systems. Indeed, language teachers may need to develop their stress-management strategies during their professional training. Furthermore, educational programmes should provide opportunities for language teachers to take professional and emotional well-being courses. Those courses should focus on bringing present awareness to an individual's well-being. They may help teachers develop their ability to regulate emotions and stress levels. In addition, there should be training courses that are designed to improve workplace climate through enhanced peer-to-peer relationships. Furthermore, there should be courses that train language teachers on how to deal with various work-related stressors such as peer conflict and heavy workloads.

While a significant impact was found in terms of the English language teachers' well-being, the findings of this study were restricted to a small number of participants. Thus, the findings should not be generalised to other English language university teachers in Saudi Arabia or to those in other language teaching contexts. Future studies on this topic may target foreign language teachers from different linguistic and cultural backgrounds. More studies in particular are needed to analyse practicing teachers' experiences in the classroom in relation to their levels of well-being. In addition, most of the findings in the present study were based on correlational analyses. Therefore, the results need to be interpreted with caution since it is not possible to assume any causal relationships between the variables. 


\section{Conclusion}

This study investigated the perception of well-being and stress of 53 university English language teachers in Saudi Arabia. This paper focused on the impact of psychological aspects of stress, the number and types of stressors, and the demographic variables related to well-being among English language teachers. This study identified the negative impact of stress and positive impact of good physical health as well as the positive effect of experiencing few stressors. However, future research is required on other cultural, organisational, and personal factors that may affect foreign language teachers' emotional well-being, particularly in monolingual contexts where foreign language learners generally benefit from scant authentic practice.

The findings highlighted the complexity of understanding how foreign language teachers perceive stress and emotional well-being, which in turn may determine the productivity and effectiveness of their language teaching. Given the increasing numbers of chronic and stressful life events, the findings may offer some insight into the type and impact of these stressors on teachers' well-being and stress. Foreign language teachers' wellbeing is a central issue that contributes to the quality of language teaching and student achievement. This study indicated that future research should adopt more holistic approaches to explore positive and negative psychological aspects that foreign language teachers may experience in the language teaching process. Further qualitative studies could explore the challenges and psychological obstacles that may impact teaching foreign languages in monolingual contexts.

\section{Declaration of Competing Interest}

None declared

\section{References}

Acheson, K., \& Nelson, R. (2020). Utilising the emotional labour scale to analyse the form and extent of emotional labour among foreign language teachers in the US public School system. In C. Gkonou, J.-M. Dewaele, \& J. King (Eds.), The emotional rollercoaster of language teaching (pp. 31-52). Multilingual Matters.

Acheson, K., Taylor, J., \& Luna, K. (2016). The burnout spiral: The emotion labour of five rural US foreign language teachers. The Modern Language Journal, 100(2), 522-537. https://doi.org/10.1111/modl.12333

Agudo, J. D. D. M. (Ed.). (2018). Emotions in second language teaching. Springer.

Al-Seghayer, K. (2014). The four most common constraints affecting English teaching in Saudi Arabia. International Journal of English Linguistics, 4(5), 17-26. http://dx.doi.org/10.5539/ijel.v4n5p17

Borg, S. (2003). Teacher cognition in language teaching: A review of research on what language teachers think, know, believe, and do. Language teaching, 36(2), 81-109. https://doi.org/10.1017/S0261444803001903

Borg, W. R., \& Gall, M. D. (1989). Educational research: An introduction (5 $5^{\text {th }}$ ed.). Longman.

Brown, J., Davis, S., \& Johnson, F. (2002). Teachers on teaching - A survey of the teaching profession. Market \& Opinion Research International.

Butler, J., \& Kern, M. L. (2014). The PERMA-Profiler: A brief multidimensional measure of flourishing [Unpublished manuscript].

Chan, D. W. (2013). Subjective well-being of Hong Kong Chinese teachers: The contribution of gratitude, forgiveness, and the orientations to happiness. Teaching and Teacher Education, 32, 22-30. https://doi. org/10.1016/j.tate.2012.12.005

Chen, J. (2016). Understanding teacher emotions: The development of a teacher emotion inventory. Teaching and Teacher Education, 55, 68-77. https://doi.org/10.1016/j.tate.2016.01.001

Cherkowski, S., \& Walker, K. (2018). Teacher wellbeing: Noticing, nurturing, and sustaining flourishing in schools. Word and Deed Press.

Cohen, S., Kamarck, T., \& Mermelstein, R. (1983). A global measure of perceived stress. Journal of Health and Social Behavior, 24(4), 385-396. https://psycnet.apa.org/doi/10.2307/2136404

Cohen, S., Murphy, M. L., \& Prather, A. A. (2019). Ten surprising facts about stressful life events and disease risk. Annual Review of Psychology, 70, 577-597. https://doi.org/10.1146/annurev-psych-010418-102857

Day, C., \& Gu, Q. (2013). Resilient teachers, resilient schools: Building and sustaining quality in testing times. Routledge. 
Day, C., \& Lee, J. (Eds.). (2011). New understandings of teacher's work: Emotions and educational change. Springer.

De Costa, P. I., \& Norton, B. (2017). Introduction: Identity, transdisciplinarity, and the good language teacher. The Modern Language Journal, 101, 3-14. https://doi.org/10.1111/modl.12368.

De Costa, P., Li, W., \& Rawal, H. (2020). Should I stay or leave? Exploring L2 teachers' profession from an emotionally inflected framework. In C. Gkonou, J.-M. Dewaele, \& J. King (Eds.), The emotional rollercoaster of language teaching (pp. 211-227). Multilingual Matters.

Dewaele, J. M. (2020). What psychological, linguistic and sociobiographical variables power EFL/ESL teachers' motivation. In C. Gkonou, J. M. Dewaele, \& J. King (Eds.), The emotional rollercoaster of language teaching (pp. 269-287). Multilingual Matters.

Dewaele, J. M., \& Mercer, S. (2018). Variation in ESL/EFL teachers' attitudes towards their students. In S. Merce,r \& A. Kostoulas (Eds.), Language teacher psychology (pp.178-195). Multilingual Matters.

Dewaele, J. M., Chen, X., Padilla, A. M., \& Lake, J. (2019). The flowering of positive psychology in foreign/second language teaching and acquisition research. Frontiers in Psychology, 10, 2128. https://doi.org/10.3389/ fpsyg.2019.02128

Dodge, R., Daly, A., Huyton, J., \& Sanders, L. (2012). The challenge of defining wellbeing. International Journal of Wellbeing, 2(3), 222-235. https://doi.org/10.5502/ijw.v2i3.4

Dörnyei, Z. (2005). The psychology of the language learner: Individual differences in second language acquisition. Lawrence Erlbaum Associates Publishers.

Dörnyei, Z. (2007). Research methods in applied linguistics: Quantitative, qualitative and mixed methodologies. Oxford University Press.

Dörnyei, Z., \& Ryan, S. (2015). The psychology of the language learner revisited. Routledge.

Elias, M. J., \& Arnold, H. (Eds.). (2006). The educator's guide to emotional intelligence and academic achievement: Social-emotional learning in the classroom. Corwin.

Evers, W.J., Brouwers, A., \& Tomic, W. (2002). Burnout and self-efficacy: A study of teachers' beliefs when implementing an innovative educational system in the Netherlands. British Journal of Educational Psychology, 72(2), 227-244. https://doi.org/10.1348/000709902158865

Falout, J., \& Murphey, T. (2018). 13 teachers crafting job crafting. In S. Mercer, \& A. Kostoulas (Eds.), Language teacher psychology (pp. 211-230). Multilingual Matters.

Fredrickson, B. L. (2004). The broaden-and-build theory of positive emotions. Philosophical Transactions of the Royal Society of London. Series B: Biological Sciences, 359(1449), 1367-1377. https://doi.org/10.1098/ rstb.2004.1512

Gardiner, M., \& Tiggemann, M. (1999). Gender differences in leadership style, job stress and mental health in male and female dominate industries. Journal of Occupational and Organisational Psychology, 72(3), 301-315. https://psycnet.apa.org/doi/10.1348/096317999166699

Gkonou, C., \& Mercer, S. (2017). Understanding emotional and social intelligence among English language teachers. British Council.

Gkonou, C., Dewaele, J. M., \& King, J. (Eds.). (2020). The emotional rollercoaster of language teaching. Multilingual Matters.

Hall, G. (2017). Exploring English language teaching: Language in action. Routledge.

Hargreaves, A. (2001). Emotional geographies of teaching. Teachers College Record, 103(6), 1056-1080. https:// psycnet.apa.org/doi/10.1111/0161-4681.00142

Herman, K. C., Hickmon-Rosa, J.E., \& Reinke, W. M. (2018). Empirically derived profiles of teacher stress, burnout, self-efficacy, and coping and associated student outcomes. Journal of Positive Behavior Interventions, 20(2), 90-100. https://doi.org/10.1177/1098300717732066

Hiver, P. (2015). Once burned, twice shy: The dynamic development of system immunity in language teachers. In Z. Dörnyei, P.D. MacIntyre, \& A. Henry (Eds.), Motivational dynamics in language learning (pp. 214-237). Multilingual Matters.

Hiver, P. (2016). The triumph over experience: Hope and hardiness in novice L2 teachers. In P. D. MacIntyre, T. Gregersen, \& S. Mercer (Eds.), Positive psychology in SLA (pp. 344-358). Multilingual Matters.

Hiver, P., \& Dörnyei, Z. (2017). Language teacher immunity: A double-edged sword. Applied Linguistics, 38(3), 405-423. https://doi.org/10.1093/applin/amv034

Holmes, T. H., \& Rahe, R. H. (1967). The social readjustment rating scale. Journal of Psychosomatic research, 11(2), 213-218. https://doi.org/10.1016/0022-3999(67)90010-4

Horwitz, E. K. (2017). On the misreading of Horwitz, Horwitz, and Cope (1986) and the need to balance anxiety research and the experiences of anxious language learners. In C. Gkonou, J. M. Dewaele, \& M. Daubney (Eds.), New insights into language anxiety: Theory, research and educational implications (pp. 31- 47). Multilingual Matters. 
Javid, C. Z., Al-Asmari, A., \& Farooq, U. (2012). Saudi undergraduates' motivational orientations towards English language learning along gender and university major lines: A comparative study. European Journal of Social Sciences, 27(2), 283-300.

Jepson, E., \& Forrest, S. (2006). Individual contributory factors in teacher stress: The role of achievement striving and occupational commitment. British Journal of Educational Psychology, 76(1), 183-197. https://doi. org/10.1348/000709905X37299

Jin, J., Mercer, S., Babic, S., \& Mairitsch, A. (2021). 'You just appreciate every little kindness': Chinese language teachers' wellbeing in the UK. System, 96, 102400. https://doi.org/10.1016/j.system.2020.102400

Jones, F., Bright, J., \& Clow, A. (2001). Stress: Myth, theory and research. Prentice Hall.

King, J. (2016). "It's time, put on the smile, it's time!": The emotional labour of second language teaching within a Japanese university. In New directions in language learning psychology (pp. 97-112). Springer. https://doi. org/10.1007/978-3-319-23491-5_7

Kyriacou, C. (2001). Teacher stress: Direction for future research. Educational Review, 53(1), 27-35. https://doi. org/10.1080/00131910120033628

Le Cornu, R. (2013). Building early career teacher resilience: The role of relationships. Australian Journal of Teacher Education, 38(4), 1-16. https://doi.org/10.14221/ajte.2013v38n4.4

MacIntyre, P., \& Gregersen, T. (2012). Affect: The role of language anxiety and other emotions in language learning. In S. Mercer, S. Ryan, \& M. Williams (Eds.), Psychology for language learning: Insights from research, theory and practice (pp. 103-118). Palgrave Macmillan.

MacIntyre, P. D., Ross, J., Talbot, K., Mercer, S., Gregersen, T., \& Banga, C. A. (2019). Stressors, personality and wellbeing among language teachers. System, 82, 26-38. https://doi.org/10.1016/j.system.2019.02.013

Maslach, C. (I 993). Burnout: A multidimensional perspective. In W. B. Schaufeli, C. Maslach, \& T. Marek (Eds.), Professional burnout: Recent developments in theory and research (pp. 19-32). Taylor \& Francis.

Mede, E. (2009). An analysis of relations among personal variables, perceived self-efficacy and social support on burnout among Turkish EFL teachers. Inonu University Journal of the Faculty of Education, 10(2), 39-52.

Mehmood, N. (2019). Factors impacting EFL teachers' self-efficacy: A theoretical perspective. English Language Teaching, 12(4), 39-48. https://doi.org/10.5539/elt.v12n4p39

Mercer, S. (2018). Psychology for language learning: Spare a thought for the teacher. Language Teaching, 51(4), 504-525. https://doi.org/10.1017/S0261444817000258

Mercer, S., \& Kostoulas, A. (Eds.). (2018). Language teacher psychology. Multilingual Matters.

Mercer, S., Oberdorfer, P., \& Saleem, M. (2016). Helping language teachers to thrive: Using positive psychology to promote teachers' professional well-being. In D. Gabryś-Barker, \& D. Gałajda (Eds.), Positive psychology perspectives on foreign language learning and teaching (pp. 213-229). Springer.

Mérida-López, S., Extremera, N., \& Rey, L. (2017). Contributions of work-related stress and emotional intelligence to teacher engagement: Additive and interactive effects. International Journal of Environmental Research and Public Health, 14(10), 1156. https://doi.org/10.3390/ijerph14101156

Moskovsky, C., \& Alrabai, F. (2009). Intrinsic motivation in Saudi learners of English as a foreign language. The Open Applied Linguistics Journal, 2(1), 1-10. http://dx.doi.org/10.2174/1874913500902010001

Moskovsky, C., Assulaimani, T., Racheva, S., \& Harkins, J. (2016). The L2 motivational self-system and L2 achievement: A study of Saudi EFL learners. The Modern Language Journal, 100(3), 641-654. https://doi. org $/ 10.1111 / \operatorname{modl} .12340$

Norton, B. (2000). Identity and language learning: Social processes and educational practice. Longman.

Oxford, R. L. (2020). The well of language teachers' emotional well-being. In C. Gkonou, J.-M. Dewaele, \& J. King (Eds.), The emotional rollercoaster of language teaching (pp. 247-268). Multilingual Matters.

Peng, J.E. (2007). Willingness to communicate in the Chinese EFL classroom: A cultural perspective. In J. Liu (Ed.), English language teaching in China: New approaches, perspectives and standards (pp. 250-269). Continuum.

Randall, P. W. (2019). Teacher stress in rural schools: A phenomenological study on stress and its effect on teacherperceived physical and mental well-being [Unpublished doctoral dissertation]. Northwest Nazarene University.

Raykov, T., \& Widaman, K. F. (2009). Issues in applied structural equation modeling research. Structural Equation Modeling: A Multidisciplinary Journal, 2(4), 289-318. https://doi.org/10.1080/10705519509540017

Rehman, M. and Alhaisoni, E. (2013). Teaching English in Saudi Arabia: Prospects and challenges. Academic Research International, 4(1), 112-118.

Reilly, E., Dhingra, K., \& Boduszek, D. (2014). Teachers' self-efficacy beliefs, self-esteem, and job stress as determinants of job satisfaction. International Journal of Educational Management, 28, 365-378. https://doi. org/10.1108/IJEM-04-2013-0053

Rooney, B. J., \& Ness Evans, A. (2018). Methods in psychological research. Sage Publications. 
Sak, R. (2018). Gender differences in Turkish early childhood teachers' job satisfaction, job burnout and organizational cynicism. Early Childhood Education Journal, 46(6), 643-653. https://doi.org/10.1007/s10643018-0895-9

Seligman, M. E. P. (2002). Authentic happiness: Using the new positive psychology to realise your potential for lasting fulfillment. ATRIA Paperback.

Seligman, M. E. P. (2011). Flourish: A visionary new understanding of happiness and well-being. Atria Books.

Shah, S. R., Hussain, M. A., \& Nasseef, O. A. (2013). Factors impacting EFL teaching: An exploratory study in the Saudi Arabian context. Arab World English Journal, 4(3), 104-123.

Skaalvik, E. M., \& Skaalvik, S. (2017). Teacher stress and teacher self-efficacy: Relations and consequences. In T. McIntyre, S. McIntyre, \& D. Francis (Eds.), Educator stress: An occupational health perspective (pp. 101-125). Springer.

Swain, M. (2013). The inseparability of cognition and emotion in second language learning. Language Teaching, 46(2), 195-207. https://doi.org/10.1017/S0261444811000486

Talbot, K., \& Mercer, S. (2018). Exploring university ESL/EFL teachers' emotional well-being and emotional regulation in the United States, Japan and Austria. Chinese Journal of Applied Linguistics, 41(4), 410-432. https://doi.org/10.1515/cjal-2018-0031

Travers, C., \& Cooper, C. (1997). Stress in teaching. In D. Shorrocks-Taylor (Ed.), Directions in educational psychology (pp. 19-32). Whurr.

Vaezi, S., \& Fallah, N.(2011). The relationship between self-efficacy and stress among Iranian EFL teachers. Journal of Language Teaching and Research, 2(5), 1168-1174. https://doi.org/10.4304/jltr.2.5.1168-1174

van Dick, R., \& Wagner, U. (2001). Stress and strain in teaching: A structural equation approach. British Journal of Educational Psychology, 71, 24- 259. https://doi.org/10.1348/000709901158505

Weiland, A. (2021). Teacher well-being: Voices in the field. Teaching and Teacher Education, 99, 103250. https:// doi.org/10.1016/j.tate.2020.103250

Werang, B. R. (2018). The effect of workload, individual characteristics, and school climate on teachers' emotional exhaustion in elementary schools of Papua. Cakrawala Pendidikan, 267399, 457-469. https://doi. org/10.21831/cp.v38i3.20635

White, C. (2018). The emotional turn in Applied Linguistics and TESOL: Significance, challenges and prospects. In J. D. D. M. Agudo (Ed.), Emotions in Second Language Teaching (pp. 19-34). Springer.

Williams, M., Mercer, S., \& Ryan, S. (Eds.). (2016). Exploring psychology in language learning and teaching. Oxford University Press.

Wolgast, A., \& Fischer, N. (2017). You are not alone: Colleague support and goal-oriented cooperation as resources to reduce teachers' stress. Social Psychology of Education, 20(1), 97-114. https://doi.org/10.1007/ s11218-017-9366-1

$\mathrm{Xu}, \mathrm{Y}$. (2018). A methodological review of L2 teacher emotion research: Advances, challenges and future directions. In J. D. D. M. Agudo (Ed.), Emotions in second language teaching (pp. 35-49). Springer.

Yaribeygi, H., Panahi, Y., Sahraei, H., Johnston, T. P., \& Sahebkar, A. (2017). The impact of stress on body function: A review. EXCLI journal, 16, 1057-1072. https://doi.org/10.17179/excli2017-480

Yu, L. (2001). Communicative language teaching in China: Progress and resistance. TESOL Quarterly, 35(1), 194198. https://doi.org/10.2307/3587868 